\title{
ORIGINAL ARTICLE \\ Role of Oral Zinc Supplementation in Reduction of Neonatal Morbidity and Mortality in Zagazig University Hospitals
}

\author{
Heba Gamal Anany ${ }^{1}$, Samar Mahmoud Sharaf ${ }^{2}$ \\ ${ }^{1}$ Pediatric Department, Faculty of Medicine, Zagazig University, Egypt \\ ${ }^{2}$ Clinical Pathology Department, Faculty of Medicine, Zagazig University, Egypt
}

Corresponding Author:

Heba Gamal Anany

Pediatric Department,

Faculty of Medicine,

Zagazig University, Egypt

hganany@gmail.com

Submit Date 2019-09-12

Revise Date 2019-11-17

Accept Date 2019-11-22

\section{ABSTRACT}

Background: Zinc is an essential cofactor for several hundred enzymes with a multitude of functions. Zinc is vitally important for proper immune functions, because of its role in skin and mucosal barrier function as well as humoral and cellular immunity. Zinc deficiency limits growth and development in infancy and childhood. Severe zinc deficiency may be observed in preterm infants especially if necrotizing enterocolitis coexisted. This study aimed to evaluate the ability of extra zinc doses to improve immunity, decrease disease incidence and death rate and show its effect on development and growth of preterm and term neonates. Methods: The present study was a single blinded randomized controlled interventional trail that was conducted in neonatal intensive care unit (NICU), pediatric department, Zagazig University children hospital in period between february 2016 to February 2017. 90 neonates were included in the study. There were randomly divided into 2 groups. Group 1 included 45 neonates who received oral zinc sulfate supplementaion on dose of $1.5 \mathrm{mg} / \mathrm{kg} /$ day. Group 2 included 45 neonates who didn't receive oral zinc supplementation. Results: This study revealed that there was a considerable decrease in morbidity and death rates in correlation with the use of zinc. Conclusions: Zinc supplementation can decrease the rate of morbidity and mortality, Zinc is vitally essential for proper immunity and growth.

Keywords: Zinc; neonatal morbidity; preterm.

\section{INTRODUCTION}

Z inc is one of the trace elements that is vital. It is the second most abundant trace element in the human body and is therefore a member of the main micronutrient subgroups that have prominence in human nutrition and health. The human body contains about $2 \mathrm{gm}$ of zinc and approximately $95 \%$ of this zinc is found within cells. About $57 \%$ of the body zinc is stored in skeletal muscles, $29 \%$ in bone and $6 \%$ in skin but zinc is found in all body tissues and fluids [1].

Various viewpoints of cellular digestion system are zinc-dependent. Zinc plays vital parts in development and growth, the immune reaction, neurological work, and reproduction. On the cellular level, the work of zinc can be partitioned into three categories: catalytic, auxiliary, and administrative. The structure and work of cell films are too influenced by zinc. Lack of zinc from natural films increments their defenselessness to oxidative harm and disables their function [2]. Real bacterial contaminations are a major cause of dying in early earliest stages; sepsis and pneumonia are mindful for $25 \%$ of dying. In spite of progresses in antimicrobial treatment, results stay destitute so improvement of uncostly and available intervensions that may progress treatment results and diminish case suffering is important [3]. Zinc given orally in the course of neonatal disease diminish length and seriousness of sickness [4]. Zinc deficiency may be observed in preterm infants with 
excessive losses- for example, those with necrotizing entero colitis [5]. Zinc intake for those preterm infants should be increased by 2 to 3 times the maintenance requirements [6]. The extra zinc dosages decrease morbidity and mortality and advance development in preterm neonates and term neonates.

Zinc can be included as an aide treatment to anti-microbial in early earliest stages with likely genuine bacterial disease because it decreases the hazard of treatment disappointment in neonatal contamination and consequently it diminishes the median hospitalization length [5].

This study aimed to evaluate the ability of extra zinc doses to improve immunity, decrease disease incidence and death rate and show its effect on development and growth of preterm and term neonates.

\section{METHODS}

The present study was a single blinded randomized controlled interventional trail that was conducted in neonatal intensive care unit (NICU), pediatric department, Zagazig University children hospital in period between february 2016 to February 2017. 90 neonates were included in the study. There were randomly divided into 2 groups. Group 1 included 45 neonates who received oral zinc sulfate supplementaion on dose of $1.5 \mathrm{mg} / \mathrm{kg} /$ day. Group 2 included 45 neonates who didn't receive oral zinc supplementation. All participants in the study had subjected to complete history taking regarding gestational age, weight at birth, Apgar score, presence of respiratory distress syndrome, mode and duration of mechanical ventilation, start of enteral feeding, time of discharge. All of babies were subjected to physical examination daily till discharge. Base line investigations were done as needed in addition to antibiotics and standard care according to hospital protocol. Data were recorded about doses and compliance as documented in the clinical charts. Diagnosis of late onset sepsis was performed according to standardized criteria. Secondary outcomes (main hospitalization period, growth and mortality) were documented. Zinc supplementation in the cases who had normal $\mathrm{Zn}$ level the dose was $1.5 \mathrm{mg} / \mathrm{kg} /$ day (recommended daily intake;
$\mathrm{RDI}$ ), in the caes who were $\mathrm{Zn}$ deficient the dose was triple RDI. Base line serum zinc level was done in zinc group before giving supplementation at fifth day of life for at least 10 days. Inclusion criteria: Preterm neonates below 37 weeks weighting 1000 gram to less than 2500 gram. Gestational age and term neonates above 36 weeks weighting more than 2500 gram on enteral feeds Exclusion criteria: Malformations, syndromes, genetic defects, critically ill conditions (defined as blood $\mathrm{Ph}<$ 7 or hypoxia with persistent bradycardia or circulatory collaps and surgical emergencies) According to the score for neonatal acute physiology.

Ethical Clearance: Written Informed consent was taken from the patient parents to participate in the study. Approval for performing the study was obtained from Pediatrics and Clinical Pathology Departments, Zagazig University Hospitals after taking Institutional Review Board (IRB) approval. The work has been carried out in accordance with the code of ethics of the world medical association (Decleration of Helsinki) for studies involving humans.

\section{Statistical Analysis}

All information for windows (SPSS Inc., Chicago, IL, USA) and MedCalc 13 for windows (MedCalc Software bvba, Ostend, Belgium) were gathered, tabulated and statistically analyzed. Using the Shapiro Walk test, data were screened for normal distribution. As frequencies and relative percentages, qualitative information were depicted. The precise Chi square and Fisher tests were used to calculate the difference between the qualitative factors as shown. Quantitative data were expressed as mean \pm SD (Standard deviation) for parametric and median and range for non-parametric data. Independent T-test and Mann Whitney test were used to calculate difference between quantitative variables in two groups for parametric and non-parametric variables respectively.

All statistical comparisons were two tailed with significance Level of P-value 0.05 suggests a substantial difference, $\mathrm{p}<0.001$ suggests a very important difference, $\mathrm{P}>0.05$ shows a substantial difference. 


\section{RESULTS}

The present study showed no statistical significant difference between both studied group regarding basic demographic data (Table 1).

This study showed a statistically significant difference among both studied groups regarding levels of $\mathrm{HB}$, platelets, total billirubin, total protein, albumin, SGOT, SGPT and CRP recorded after end of Zn supplementation (Table 2).

This study showed a statistical significant difference among both studied groups regarding morbidities occurred, as $40 \%$ of group I (received zinc) complained of late onset sepsis and $13.3 \%$ complained of necrotizing enterocolitis compared to $75.6 \%$ and $37.8 \%$ respectively among their controls. Also only $4.4 \%$ of group I suffered from more than one problem (sepsis, NEC, pneumonia) at the same time, on contrary to $68.9 \%$ among group II (Figure 1).

This study showed there was statistical significant difference among them regarding daily weight gain, it was $16.2 \mathrm{gm} /$ day \pm $8.25 \mathrm{gm}$ among group I (received zinc), compared to $4.04 \pm 4.7 \mathrm{gm} /$ day among controls

(Figure 2).

Also there was a high statistical significant difference between both groups regarding length of hospital stay, it was longer among controls $24.9 \pm 6.02$ days ( Figure 3).

This study showed that prevalence of mortality was higher among controls that occurred in $24.4 \%$.compared to $11.1 \%$ only mortality rate among group I (received zinc), with a statistical significant difference total mortality was16 from 90 (17.8\%)(Figure 4).

Table 1. Basic demographic data among both studied groups

\begin{tabular}{|c|c|c|c|c|c|c|}
\hline \multirow[t]{2}{*}{ Variables } & \multicolumn{2}{|c|}{ Group I ZINC) N=45 } & \multicolumn{2}{|c|}{ Group II Controls) N=45 } & \multirow[t]{2}{*}{$x^{2}$} & \multirow{2}{*}{$\begin{array}{c}\mathbf{P} \\
\text { value }\end{array}$} \\
\hline & $\mathbf{N}$ & $\%$ & $\mathbf{N}$ & $\%$ & & \\
\hline $\begin{array}{l}\text { Sex } \\
\qquad \begin{array}{l}\text { Male } \\
\text { Female }\end{array}\end{array}$ & $\begin{array}{l}22 \\
23\end{array}$ & $\begin{array}{l}48.9 \\
51.1\end{array}$ & $\begin{array}{l}20 \\
25\end{array}$ & $\begin{array}{l}44.4 \\
55.6\end{array}$ & 0.179 & 0.833 \\
\hline $\begin{array}{l}\text { Mode of delivery } \\
\text { NVD } \\
\text { CS }\end{array}$ & $\begin{array}{l}14 \\
31\end{array}$ & $\begin{array}{l}31.1 \\
68.9\end{array}$ & $\begin{array}{l}22 \\
23\end{array}$ & $\begin{array}{l}48.9 \\
51.1\end{array}$ & 2.96 & 0.132 \\
\hline $\begin{array}{l}\text { Maturity } \\
\text { Mature } \\
\text { Pre-mature }\end{array}$ & $\begin{array}{l}20 \\
25\end{array}$ & $\begin{array}{l}44.4 \\
55.6\end{array}$ & $\begin{array}{l}13 \\
32\end{array}$ & $\begin{array}{l}28.9 \\
71.1\end{array}$ & 2.34 & 0.179 \\
\hline $\begin{array}{l}\text { BW group } \\
\text { VLBW } \\
\text { LBW } \\
\text { Average weight }\end{array}$ & $\begin{array}{c}2 \\
26 \\
17\end{array}$ & $\begin{array}{c}4.4 \\
57.8 \\
37.8\end{array}$ & $\begin{array}{c}2 \\
27 \\
16\end{array}$ & $\begin{array}{c}4.4 \\
60 \\
35.6\end{array}$ & 0.049 & 0.976 \\
\hline & & & & & t-test & \\
\hline $\begin{array}{c}\text { Gestational age } \\
\text { Mean }\end{array}$ & \multicolumn{2}{|c|}{$33.5 \pm 3.34$} & \multicolumn{2}{|c|}{$33.4 \pm 3.21$} & 0.128 & 0.899 \\
\hline $\begin{array}{c}\text { Birth weightlkg } \\
\text { Mean }\end{array}$ & \multicolumn{2}{|c|}{$2.06 \pm 0.75$} & \multicolumn{2}{|c|}{$1.88 \pm 0.72$} & 1.14 & 0.257 \\
\hline
\end{tabular}


Table 2. Difference in laboratory data after end of nutrition program between both studied groups

\begin{tabular}{|l|c|c|c|c|}
\hline & Group I=45 & Controls=45 & & \\
\hline HB & $11.6 \pm 1.12$ & $10.3 \pm 1.93$ & 3.89 & $0.000^{* *}$ \\
\hline Platelet count & $175.6 \pm 50.4$ & $101.3 \pm 76.2$ & MW 5.45 & $0.000^{* *}$ \\
\hline WBCs & $16.82 \pm 10.3$ & $15.04 \pm 6.9$ & MW 0.923 & 0.359 \\
\hline Total billirubin & $6.5 \pm 1.86$ & $10.4 \pm 5.1$ & MW 4.86 & $0.000^{* *}$ \\
\hline Total protein & $4.12 \pm 0.42$ & $3.52 \pm 0.67$ & 5.09 & $0.000^{* *}$ \\
\hline Albumin & $2.92 \pm 0.33$ & $2.31 \pm 0.57$ & 6.18 & $0.001^{* *}$ \\
\hline SGOT & $21.5 \pm 33.6$ & $72.4 \pm 54.8$ & MW 5.31 & $0.000^{* *}$ \\
\hline SGPT & $43.8 \pm 44.04$ & $100.1 \pm 68.2$ & MW 4.65 & $0.000^{* *}$ \\
\hline Serum creatinin & $0.93 \pm 0.41$ & $1.04 \pm 0.35$ & 1.32 & 0.191 \\
\hline CRP & $17.5 \pm 36.7$ & $69.1 \pm 59.2$ & MW 4.97 & $0.000^{* *}$ \\
\hline
\end{tabular}

**P-value $<0.001$ is high significant

Table 3. Difference in mortality occurred between both studied groups.

\begin{tabular}{|c|c|c|c|c|c|c|}
\hline & \multicolumn{2}{|c|}{ Group I (ZINC) } & \multicolumn{2}{|c|}{ Group II (control) } & $x^{2}$ & $P$ value \\
\hline & $\mathbf{N}$ & $\%$ & $\mathbf{N}$ & $\%$ & & \\
\hline Mortalit & 5 & 11.1 & 1 & 24.4 & 8.736 & $0.003^{*}$ \\
\hline $\mathbf{y}$ & 40 & 88.9 & 1 & 75.6 & & \\
\hline
\end{tabular}

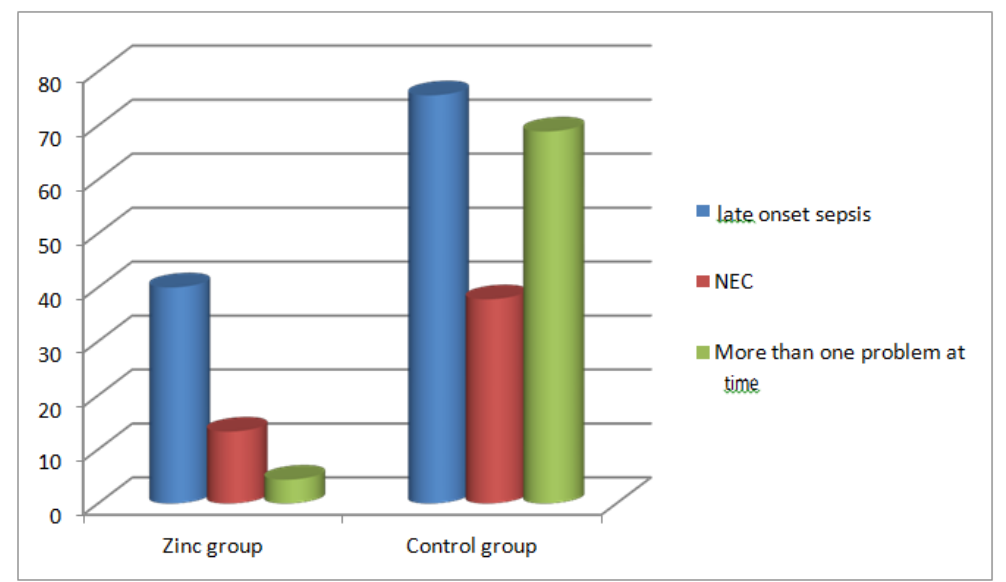

Figure 1. Difference in morbidities occurred between both studied groups. 


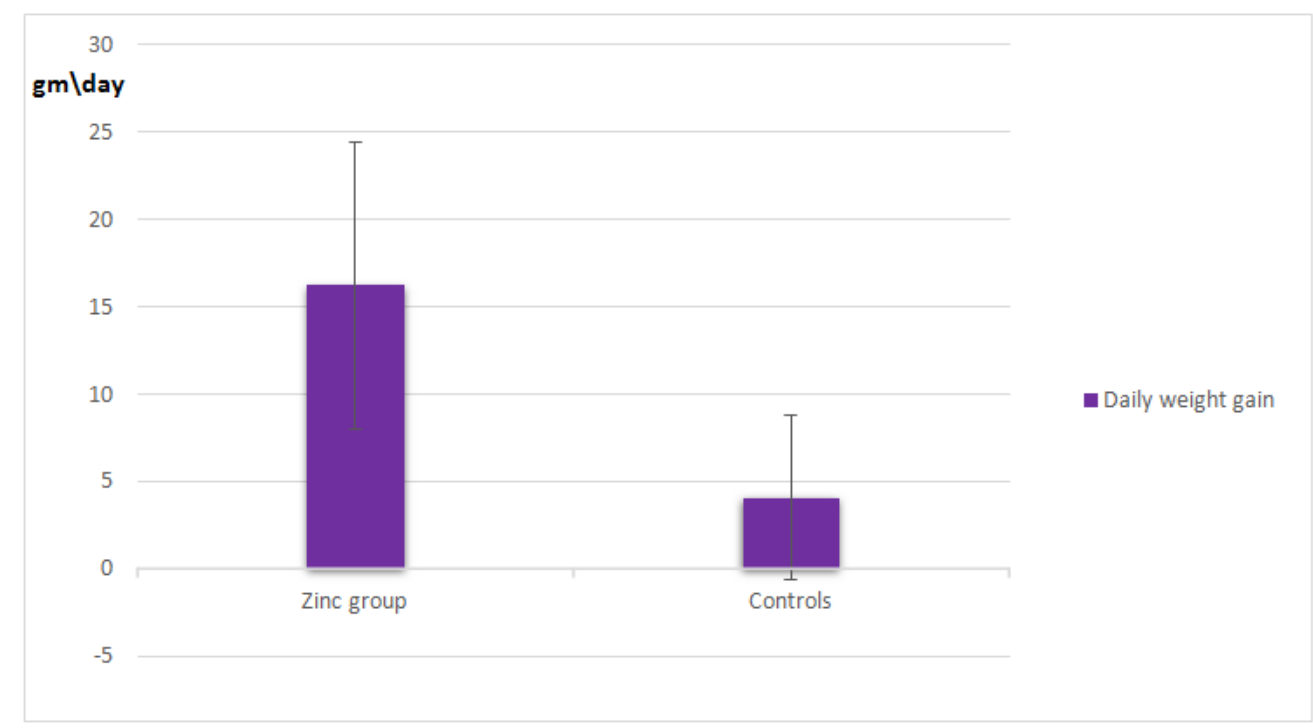

Figure 2. Difference in daily weight gain among both studied groups.

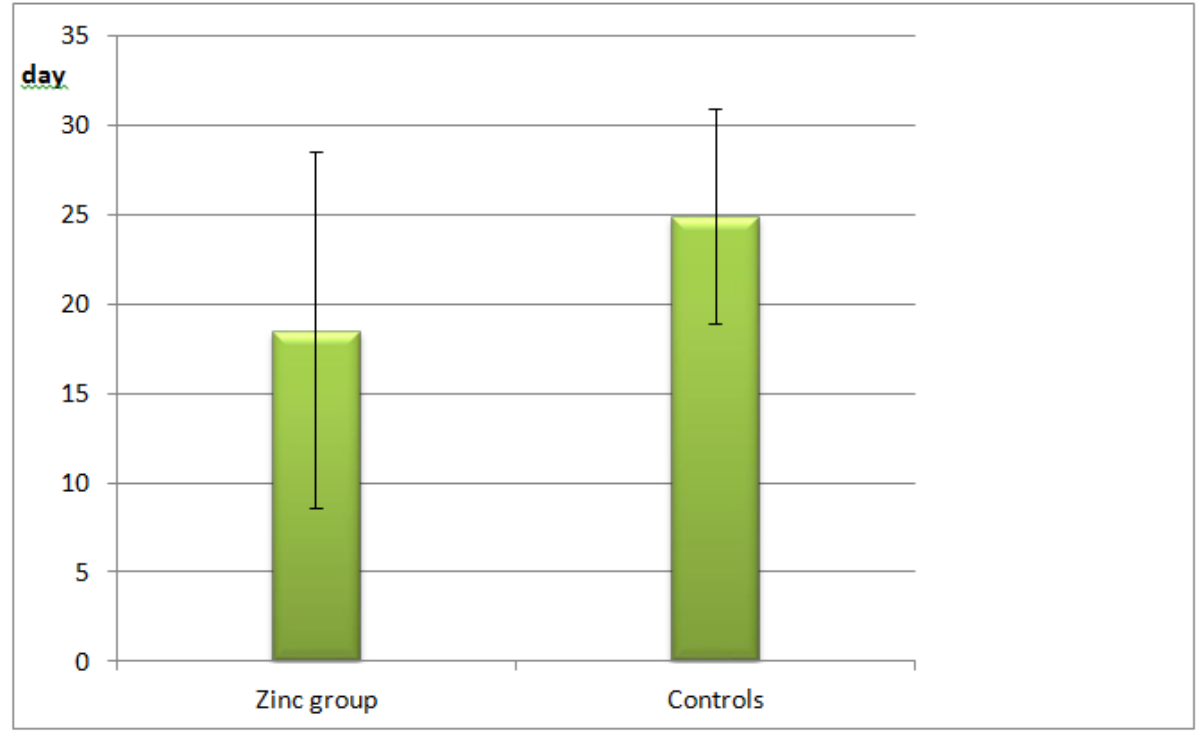

Figure 3. Difference in hospital stay among both studied groups. 


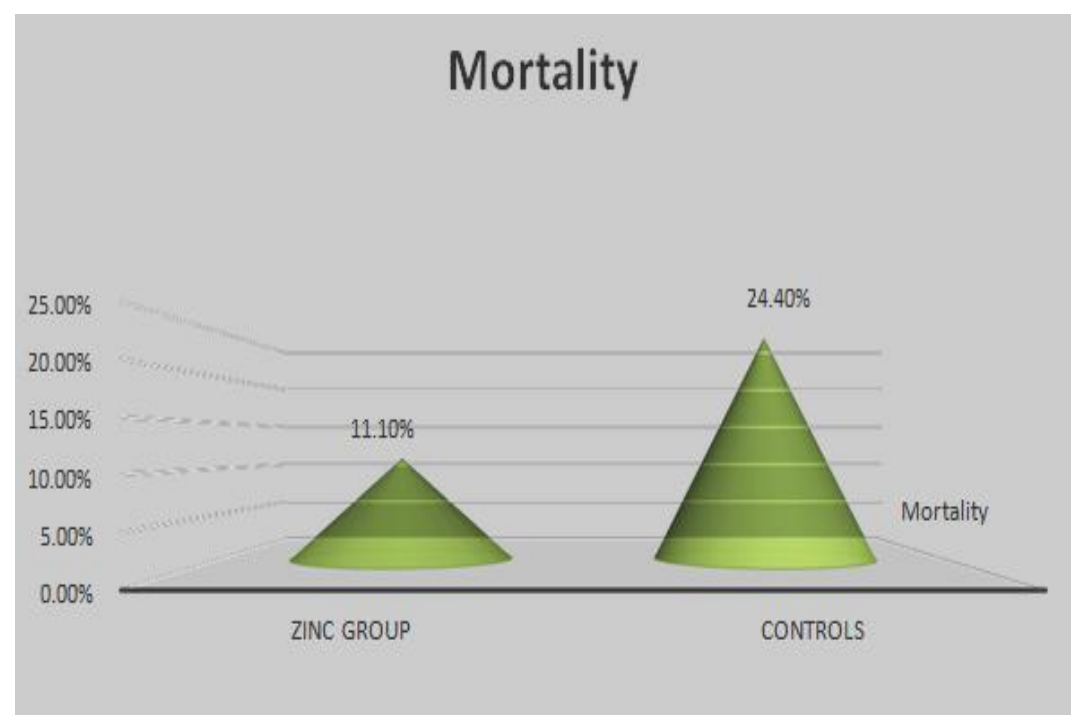

Figure 4. Difference in mortality prevalence between both studied groups.

\section{DISCUSSION}

Zinc is an essential ingredient in the cell engineering and work within the living being. It is needed vitally for the generation of several proteins, counting phosphatases, metalloproteinases, oxidoreductases, and transferases, which are included in protein synthesis, nucleic corrosive digestion system, and resistant capacities. In expansion, it could be a basic ingredient of different enzymes, hormones, and nucleotides [10].

Zinc insufficiency is common in youthful newborn children within the creating world and is associated with decrease immunity and expanded rates of genuine illnesses. Low zinc serum level have been watched within the blood of low birth weight (LBW) infant. For few reasons, preterm newborn children have moderately extra zinc dietary necessities. Approximately 55\% of zinc content of fetus is obtained in last trimester of pregnancy [11].

Zinc insufficiency has a predatory effect on the endocrine system, lead to reterded growth. Zinc is essentially important in gene reproduction and it is the most prevalent trace elements exist in the brain [12].

Malnutrition is one of the major open wellbeing challenges and the foremost common immunodeficiency malady. Micronutrient lacks (as $\mathrm{Zn}$ ) are the major chance variables for lack of healthy sustenance, which are mindful of more than one third of passing in children beneath five in creating countries [13]. This study found that respiratory trouble disorder and mechanical ventilation were essentially visit in no zinc bunch compared to zinc bunch.

Islam et al.[7] and Sazawal and Black [8] compared the impact of zinc administration orally on development of premature babies. They concluded that zinc supplementation for low birth weight babies is effective to enhance the growth in early months of life.

Terrin et al. [9] Investigated the role of zinc supplementation in decreasing diseases and death rate in preterm neonates. They concluded that oral extra zinc doses given reduces infection and death rate neonates and enhance weight gain.

These discoveries comprise with Banupriya et al., [14] that found that mechanical ventilation were higher in non zinc bunch. This study found that platelets were essentially higher in zinc gather compared to no zinc bunch.

Fisk, [15] suggested that zinc promotes platelet production, and zinc deficiency can cause reduction in platelet count.

This study found a significant difference were found only in weight after zinc supplementation and a minimal increase in length of neonates but not significant.

This study found a critical contrast among both considered bunches with respect to morbidities happened, as $40 \%$ of gather gotten zinc complained of late onset sepsis and $13.3 \%$ complained of necrotizing 
enterocolitis compared to $75.6 \%$ and $37.8 \%$ sequentially among their controls.

This study also noted that treatment failure was significantly higher in control group compared to zinc group.

Infants with bacterial infection on antibiotics, aged from 7 to $120 \mathrm{~d}$ were randomized into zinc and placebo groups by Bhatnagar et al., [16]. They revealed a lesser incidence of treatment failure in the zinc group (10\%) compared to the placebo group $(17 \%)$, and this was in agreement with our study

This study documented that the mortality rate and hospital stay were significantly higher in no zinc group, consisting with El Frargy and Soliman,[17] they found that the death incidence was significantly fewer in zinc gather $(10 \%)$ in comparison with non zinc gather (18\%).

This study findings demonstrate a critical decrease in horribleness and death rate related with the administration of extra zinc doses to premature babies. This study findings comes about concur with El-Frargy and Soliman [17], past said thinks about benefits of zinc administration during neonatal period .

\section{CONCLUSION}

That zinc supplementation reduces the rate of morbidity and mortality, Zinc is vitally essential for defense functions and growth.

\section{LIMITATION OF STUDY}

The conclusions of this study were limited by the small number of observations and we only followed up the patients until discharge.

\section{RECOMMENDATION}

Prescribe- zinc supplementation for at least 10 days by doses equal triple recommended daily intake for at risk neonates especially prematures to obtain better prognosis.

\section{Declaration of interest}

The authors report no conflicts of interest. The authors alone are responsible for the content and writing of the paper.

Funding information: None declared

\section{REFERENCES}

1. Mason P. Physiological and medicinal zinc. The Pharma J, 2006; 276: 271-4.

2. Lichten A. Cousins J. Mammalian zinc transporters: nutritional and physiologic regulation. Annu Rev Nutr. 2009; 29: $153-$ 76.

3. Bassani DG, Kumar R, Awasthi S, Morris SK, Paul VK. Causes of neonatal and child mortality in India: a nationally representative mortality survey. Lancet. 2010; 376(9755):1853-60.

4. Mehta K, Bhatta NK, Majhi S, Shrivastava MK, Singh RR. Oral zinc supplementation for reducing mortality in probable neonatal sepsis: a double blind randomized placebo controlled trial. Indian Pediatr. 2013; 50:390-3.

5. Gulani A, Bhatnagar S, Sachdev HPS. Neonatal zinc supplementation for prevention of mortality and morbidity in breastfed low birth weight infants: systematic review of randomized controlled trials. Indian Pediatr. 2011;48:111-7.

6. Basnet S, Shrestha PS, Sharma A, Mathisen M, Prasai R, Bhandari N, et al., A randomized controlled trial of zinc as adjuvant therapy for severe pneumonia in young children. Pediatrics. 2012; 129:701-8.

7. Islam MN, Chowdhury MA, Siddika M, Qurishi SB, Bhuiyan MK, Hoque MM, et al., Effect of oral zinc supplementation on the growth of preterm infants. Indian Pediatr. 2010; 47 (10): 845-9.

8. Sazawal S, Black R. Effect of oral zinc supplementation on the growth of preterm infants. Indian Pediatr. 2010; 47: 841- 2.

9. Terrin G, Berni CR, Passariello A, Messina F, Conti MG, Caoci $S$, et al., Zinc supplementation reduces morbidity and mortality in very-low-birth-weight preterm neonates: a hospital-based randomized, placebo-controlled trial in an industrialized country. The American journal of clinical nutrition, 2013; 98(6), 1468-74.

10. Hambidge M. Human zinc deficiency. J Nutr 2000; 130:1344-9.

11. Islam MN, Chowdhury MA, Siddika M, Qurishi SB, Bhuiyan MK, Hoque MM, et al., Effect of oral zinc supplementation on the growth of preterm infants. Indian Pediatr. 2010; 47(10):845-9.

12. Sur D, Gupta DN, Mondal SK, Ghosh S, Manna B, Rajendran K, et al. Impact of zinc supplementation on diarrhoeal morbidity and growth pattern of low birth weight infants in Kolkata, India: A randomized, double-blind, placebocontrolled, community-based study. Pediatrics 2003; 112: 1327-32. 
13. Bonaventura $\mathrm{P}$, Benedetti $\mathrm{G}$, Albarède F, Miossec P. Zinc and its role in immunity and inflammation. Autoimmun Rev. 2015;14(4):277-85.

14. Banupriya N, Bhat BV, Benet BD, Catherine C, Sridhar MG, Parija SC. Short Term Oral Zinc Supplementation among Babies with Neonatal Sepsis for Reducing Mortality and Improving Outcome - A Double-Blind Randomized Controlled Trial. Indian J Pediatr. 2018; 85(1):5-9.

15. Fisk M. Foods to Increase Blood Platelets. 2017.

https://www.livestrong.com/ article/127280-foods- increase-bloodplatelets.

16. Bhatnagar S, Wadhwa N, Aneja S, Lodha R, Kabra SK, Natchu UCM, et al., Zinc as adjunct treatment in infants aged between 7 and 120 days with probable serious bacterial infection: a randomised, double-blind, placebo-controlled trial. The Lancet, 2012; 379(9831), 2072-8.

17. El Frargy MS, Soliman NA. Zinc supplementation as an adjuvant treatment in neonatal sepsis. Curr Pediatr Res 2017; 21(1): 93-8.

To Cite This Article: Heba GA, Samar MS.Role of Oral Zinc Supplementation in Reduction of Neonatal Morbidity and Mortality in Zagazig University Hospitals.ZUMJ 2020;26(1);140-147.DOi: 10.21608/zumj.2019.16235.1454 